Research Article

\title{
Energy Dissipation and Failure Characteristics of Layered Composite Rocks under Impact Load
}

\author{
Wenjie Liu $\mathbb{D}^{1,3,4}$ Ke Yang $\mathbb{D}^{1,2,3,4}$ Wei Zhen $\mathbb{D}^{1,3,4}$ Xiaolou Chi $\mathbb{D}^{1,3,4}$ Rijie Xu ${ }^{1,},,^{1,3,4}$ \\ and $X$ in $L v$ (D) $1,3,4$ \\ ${ }^{1}$ State Key Laboratory of Mining Response and Disaster Prevention and Control in Deep Coal Mines, \\ Anhui University of Science and Technology, Huainan 232001, China \\ ${ }^{2}$ Institute of Energy, Hefei Comprehensive National Science Center, Hefei 230031, Anhui, China \\ ${ }^{3}$ National \& Local Joint Engineering Research Center of Precision Coal Mining, Anhui University of Science and Technology, \\ Huainan 232001, Anhui, China \\ ${ }^{4}$ Key Laboratory of Mining Coal Safety and Efficiently Constructed by Anhui Province and Ministry of Education, \\ Anhui University of Science and Technology, Huainan 232001, China
}

Correspondence should be addressed to Ke Yang; keyang2003@163.com

Received 16 July 2021; Accepted 1 November 2021; Published 15 November 2021

Academic Editor: Jianwei Cheng

Copyright (C) 2021 Wenjie Liu et al. This is an open access article distributed under the Creative Commons Attribution License, which permits unrestricted use, distribution, and reproduction in any medium, provided the original work is properly cited.

Horizontal layered composite rock samples composed of white and black sandstones with large differences in physical and mechanical properties were tested to explore the dynamic characteristics of layered composite rocks under impact load. Using the split Hopkinson pressure bar test system, the dynamic compression tests of two incident states of stress waves, that is, stress waves from white sandstone to black sandstone $(\mathrm{W} \longrightarrow \mathrm{B})$ and from black sandstone to white sandstone $(\mathrm{B} \longrightarrow \mathrm{W})$, were designed and carried out under different impact velocities. Combining the ultrahigh-speed photography system and digital photogrammetry for deformation measurement (DPDM), we obtained the stress wave propagation characteristics, failure characteristics, and particle size distribution characteristics of broken rocks of the composite rocks under the two conditions. The experimental results were compared and analyzed, while stresses and strength conditions at the interface of the composite rock samples were theoretically assessed, yielding the following main findings. The energy dissipation pattern of composite rock had an obvious strain rate effect. The reflected energy and fragmentation energy density of composite rock increased approximately as quadratic functions of the incident energy. Affected by the wave impedance matching relationship, the $\mathrm{W} \longrightarrow \mathrm{B}$ and $\mathrm{B} \longrightarrow \mathrm{W}$ samples were significantly different in terms of the stress wave shape, energy dissipation, average particle size, and fractal dimension of the broken rocks at low impact velocities. However, with an increase in the impact velocities, the two gradually shared the same behavior. When composite rock samples deformed and failed, the macrocracks mostly initiated from the white sandstone. When the crack tip stress of the white sandstone at the interface exceeded the strength of the weakened black sandstone, the crack continued to develop through the two-phase rock interface due to the difference in Poisson's ratios. The damage degrees and failure modes of the two parts of composite rocks were different: black sandstone was prone to tensile splitting with local shear failure, while white sandstone exhibited shear failure with local tensile splitting. The damage degree of white sandstone exceeded that of black sandstone.

\section{Introduction}

Layered composite rocks are mostly natural engineering geological bodies consisting of multiple layers of rocks with different lithologies and thicknesses deposited in a certain order and manner [1-3]. In underground coal mining, the excavation of layered composite rocks is inevitable. Affected by blasting excavation, activation of faults, and breaking of thick and hard roofs, roadways are often subjected to dynamic (impact) loads acting as stress waves of various velocities and frequencies. The structural complexity of layered composite rocks implies that their characteristics of stress wave propagation and attenuation are notably different from those of single rocks. Therefore, studying the dynamic 
response characteristics of layered composite rocks is of great significance to the tunneling and support in roadways of layered composite rocks $[4,5]$.

Through theoretical analysis [6-9], numerical simulation [10-12], physical analog modeling [13-15], laboratory tests [16-23], and other methods, comprehensive and in-depth research on layered composite rocks and single rocks has been performed worldwide. Thus, in 1960, Jaeger [6] proposed the shear failure criterion for heterogeneous rocks, while in 2001, Tien and Kuo [7] proposed the shear failure criterion for transversely isotropic rocks. In 2014, the latter criterion was revised by Saeidi et al. [8] based on laboratory test results. In recent works on numerical simulation, Cao et al. [10] used compressive-shear tests and PFC2D numerical simulation methods to analyze the influence of bedding angle on the mechanical characteristics, crack propagation patterns, and acoustic emission response behaviors of transversely isotropic rock with cuts at both ends. In 2021, Xu et al. [11] used the particle flow discrete element numerical simulation method combined with the uniaxial compression tests on a transversely isotropic rock with prefabricated fractures. The influence of cracks and weak surfaces on the rock fracture shape was analyzed, six failure morphologies were determined, and the crack evolution process of each morphology was studied based on matrix tensor analysis. Maazallahi and Majdi [12] analyzed the deformation characteristics of a circular tunnel in a transversely isotropic rock under hydrostatic pressure and nonhydrostatic pressure. It was pointed out that the greater the stress anisotropy index, the greater the difference between the maximum and minimum displacements of the tunnel surface. In recent works on physical analog modeling, Shen et al. [15] prepared transversely isotropic similar material samples formed by the interbedding of two similar materials. Triaxial compression tests were carried out on five sets of transversely isotropic samples with different bedding angles, and the evolution of mechanical parameters, fracture types, and failure morphology of inclined interbedded similar rock material was analyzed. On laboratory tests research, Yang et al. [16] combined acoustic emission technology and DIC technology to carry out conventional triaxial compression tests, confining pressure reduction triaxial tests, and Brazil disc splitting tests on transversely isotropic shales with different bedding angles. They reported that the bending angle greatly influenced the elastic modulus, tensile strength, compressive strength, and failure morphology of the rock. When the confining pressure was reduced and the axial pressure was increased, the energy dissipation was larger and the damage was more severe, compared with the loading where the axial pressure was fixed while the confining pressure was reduced. Based on the uniaxial compression test of shale-coal layered composite sample combined with an acoustic emission monitoring device, Chen et al. [17] analyzed the stress-strain curve characteristics, the macroscopic initiation, failure pattern, and the progressive failure characteristics of the coal composite rocks. The drilling and blasting methods are often used when excavating the roadway in the rock mass. In engineering construction, more attention is paid to the failure characteristics of rocks under dynamic load. To this end, Li et al. [24] carried out a dynamic impact test study on single-joint red sandstone, which showed that the presence of joint weakened the dynamic compressive strength of sandstone. With an increase in the joint inclination angle, the degree of stress wave attenuation increased. The sandstone affected by the shock stress wave was mostly damaged by the tensile rib spalling. Han et al. [25] studied the dynamic characteristics of sandstone with different cement mortar thicknesses. As the thickness of the cementation increased, the failure morphology of the sandstone gradually changed from local tensile spalling to penetrating splitting.

Most of the above studies were focused on the mechanical characteristics, energy dissipation, failure criteria, and constitutive relations of layered composite rocks under static load, as well as dynamic characteristics of single rocks or jointed rocks under dynamic load. However, there are quite a few studies on the impact dynamics of layered composite rocks. This paper combined the SHPB test system with an ultrahigh-speed camera and digital photogrammetry for deformation measurement to carry out the impact compression tests on layered composite rock samples. The stress characteristics and strength conditions of composite rocks were analyzed theoretically. Also, the law of energy dissipation, deformation, and fracture characteristics of layered composite rocks under the two stress wave incident states, that is, stress waves passing from white sandstone to black sandstone $(\mathrm{W} \longrightarrow \mathrm{B})$ and from black sandstone to white sandstone $(\mathrm{B} \longrightarrow \mathrm{W})$, were revealed. The research results can provide a certain reference for rock-breaking and support of composite rock projects.

\section{SHPB Test of Layered Composite Rocks}

2.1. Sample Preparation. The sandstone samples required for the test were taken from the roof of the coal seam $4 \#$ in the Hujiahe Coal Mine, Binchang, Shaanxi Province of China. To control the discreteness of the rock samples, the unweathered rock samples with good integrity were wax-sealed on-site and transported to the laboratory. They were processed into cylindrical samples of $\Phi 50 \mathrm{~mm} \times 25 \mathrm{~mm}$ dimensions via cutting, drilling, and grinding procedures. Then, epoxy resin [24] was used to bond the sandstone single-body samples to form $\Phi 50 \mathrm{~mm} \times \mathrm{h} 50 \mathrm{~mm}$ "black sandstone-white sandstone" horizontal layered composite samples. During the sample bonding process, the amount of epoxy resin was strictly controlled to ensure that the twophase rock components were fully and uniformly bonded while minimizing the binder thickness effect. When each sample was processed, the size and processing accuracy of the sandstone single-body sample and the composite rock sample were required to meet the standard requirements recommended by ISRM. At the same time, sandstone samples for the uniaxial compression test and Brazil splitting test were prepared. The main physical and mechanical parameters of black sandstone and white sandstone were measured, as shown in Table 1. To use the digital photogrammetry for deformation measurement for analyzing the deformation and failure pattern of the samples, uniformly 
TABLE 1: Mechanical parameters of black sandstone and white sandstone samples.

\begin{tabular}{lcccccc}
\hline $\begin{array}{l}\text { Lithology } \\
\text { White }\end{array}$ & $\begin{array}{c}\text { Compressive strength } \\
(\mathrm{MPa})\end{array}$ & $\begin{array}{c}\text { Elastic modulus } \\
(\mathrm{GPa})\end{array}$ & $\begin{array}{c}\text { Tensile strength } \\
(\mathrm{MPa})\end{array}$ & $\begin{array}{c}\text { Poisson's } \\
\text { ratio }\end{array}$ & $\begin{array}{c}\text { Longitudinal wave velocity } \\
\left(\mathrm{m} \cdot \mathrm{s}^{-1}\right)\end{array}$ & $\begin{array}{c}\text { Density } \\
\left(\mathrm{kg} \cdot \mathrm{m}^{-3}\right)\end{array}$ \\
$\begin{array}{l}\text { sandstone } \\
\begin{array}{l}\text { Black } \\
\text { sandstone }\end{array}\end{array}$ & 44.62 & 6.65 & 4.06 & 0.16 & 3946 & 2677 \\
\hline
\end{tabular}

distributed speckles with random size were made on the surface of each sample [26-28]. Figure 1 shows the composite rock samples after processing.

2.2. Test System and Plan. The impact compression tests of layered composite rocks were performed using the split Hopkinson pressure bar (SHPB) test system and an ultrahigh-speed camera system. As shown in Figure 2, the incident bar, transmitted bar, and spindle punch of the SHPB test system were made of high-strength alloy steel with a density of $7800 \mathrm{~kg} / \mathrm{m}^{3}$, an elastic modulus of $210 \mathrm{GPa}$, and a longitudinal wave velocity of $5190 \mathrm{~m} / \mathrm{s}$. The bar diameter was $50 \mathrm{~mm}$, and the impact waveform was a sine. During the tests, the amplitude and impact velocities of the incident stress wave were controlled by adjusting the gas pressure inside the high-pressure air chamber or changing the spindle punch position. The strain signal generated during stress wave propagation in the incident and transmitted bars was collected by SG1, SG2 dynamic strain gauges, and SDY2107 A ultrahigh dynamic strainmeter, which was then displayed and stored by Yokowaga-DL850 E oscilloscope. The ultrahigh-speed camera system was composed of a FASTCAMSA-Z high-speed camera, flashlight, synchronous trigger control system, and so on. Before the test, the shooting speed of the high-speed camera was set to 120000 fps and the image resolution was set to $256 \times 408$ pixels to ensure that the camera could capture the entire deformation and failure process of the sample. When the stress wave propagated in the incident bar, the strain gauge transmitted the strain signal to the super dynamic strain gauge, which converted it into a voltage signal to synchronously trigger the high-speed camera and flashlight.

The image processing technology adopted in this paper is the digital photogrammetry for deformation measurement (DPDM) technology [29]. DPDM system is mainly composed of image acquisition hardware system and postprocessing software system. The hardware system of image acquisition mainly includes digital camera and lighting equipment. DPDM software includes PhotoInfor and PostViewer processing software. Image analysis software PhotoInfor is specially used for the processing and analysis of punctuation digital photos. Its main functions include image binarization, direct pick-up of punctuation recognition parameters, recognition of centroid coordinates, corresponding punctuation sorting, elimination of repeated points, image calibration, displacement calculation, quadrilateral mesh generation for strain calculation, and strain calculation. PostViewer, as a postprocessing program of image analysis result data, can generate and display contour

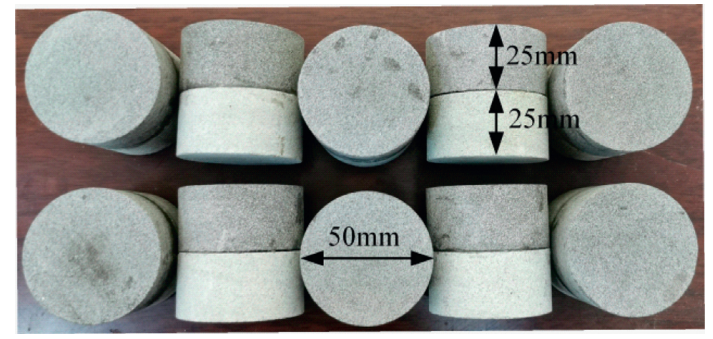

FIgURE 1: "Black sandstone-white sandstone" layered composite rock samples.

lines, cloud maps, deformation grids, vector maps, and so on. Meanwhile, it also has query, statistical analysis, data extraction, batch processing, and output processing functions.

As shown in Figure 3, according to the incident direction of the stress wave, when the incident stress wave propagated from black sandstone to white sandstone, the respective test group was marked as $\mathrm{B} \longrightarrow \mathrm{W}$, and vice versa as $\mathrm{W} \longrightarrow \mathrm{B}$. A preliminary test was carried out on the layered composite rock before the main impact tests, which revealed that when the impact pressure exceeded $0.6 \mathrm{MPa}$, large-scale macrocracks appeared in the white sandstone samples. Based on the preliminary test results, the impact compression tests of the layered composite rocks were designed with five impact pressures of $0.40,0.50,0.60,0.70$, and $0.90 \mathrm{MPa}$. To reduce the contingency and improve the accuracy of the test results, at least three sets of parallel tests were performed for each impact pressure. After the test, valid test results were selected for analysis. Before impact loading, a small amount of petroleum jelly was applied to the bar-sample contact to reduce the friction effect on the test results.

2.3. Verification of Dynamic Stress Balance. The stress equilibrium state at both ends of the sample before its impact damage is the premise of the one-dimensional stress wave hypothesis and the stress (strain) uniformity hypothesis, which is necessary to obtain reliable test results. Figure 4 shows the stress at both ends of a typical impact compression test sample of layered composite rocks. It can be seen that, during the impact loading process of layered composite rocks, the sum of the incident and reflected stresses was approximately equal to the transmitted stress. Therefore, it can be considered that the sample was in a state of dynamic stress balance and satisfied the stress equilibrium condition. 


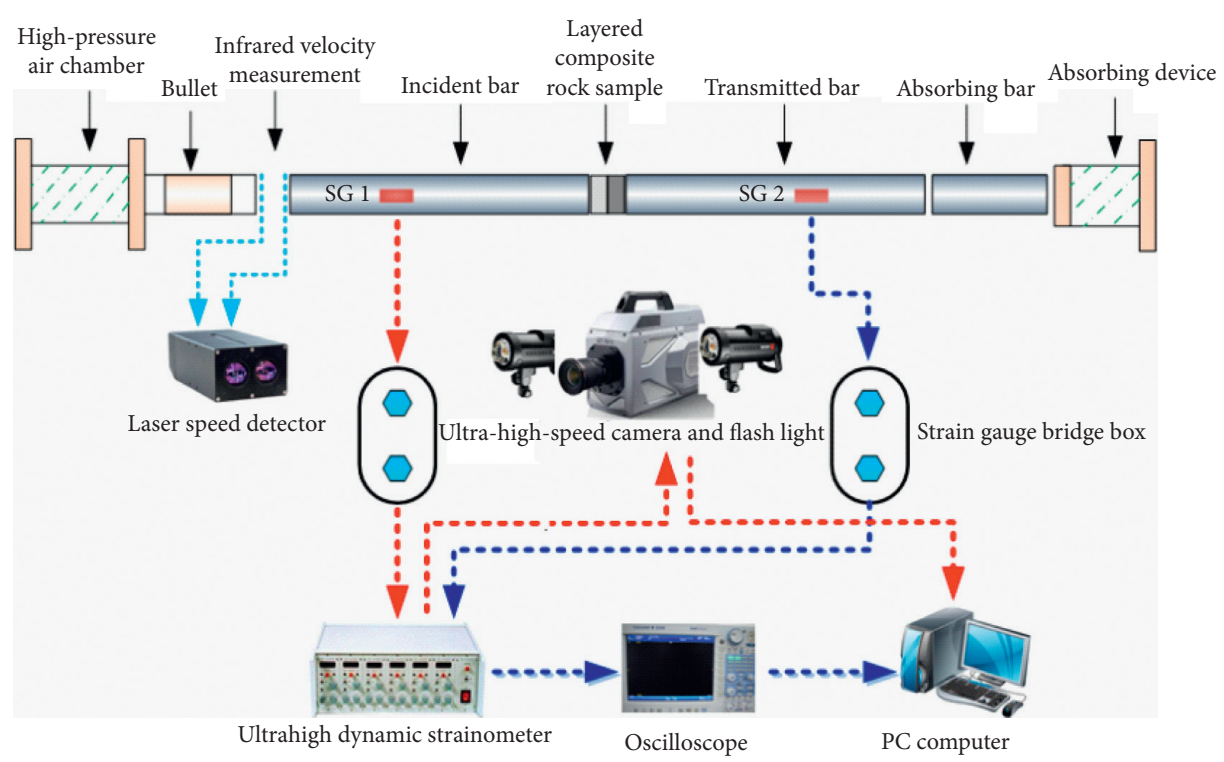

FIGURE 2: SHPB and high-speed photography system.

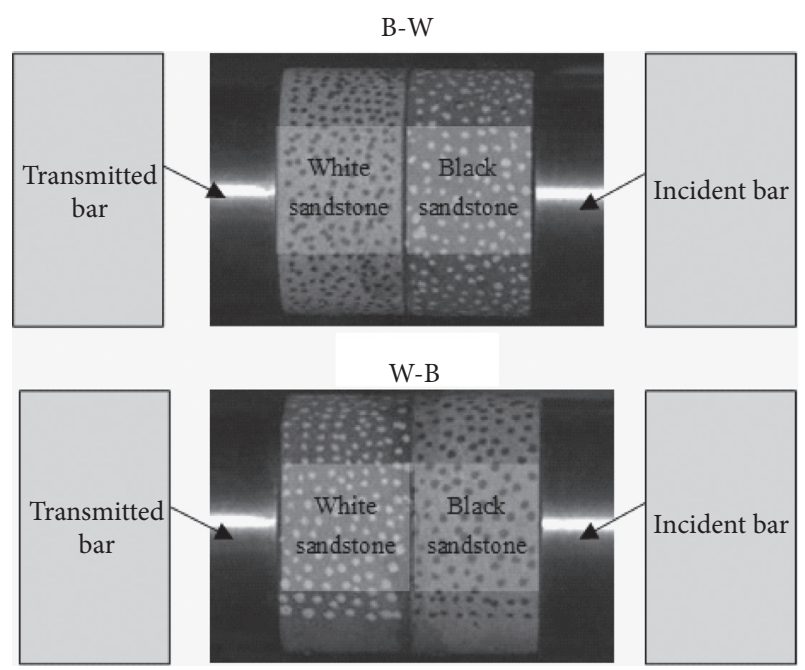

FIGURE 3: Schematic diagram of sample grouping.

\section{Test Results and Analysis}

3.1. Analysis of Stress Wave Propagation Characteristics. Comparing and analyzing the stress waveforms of layered composite rocks under different impact velocities (Figure 5), one can see that, with an increase in impact velocity, the amplitudes of the incident, reflected, and transmitted waves of the layered composite rocks under study gradually increased. Under the same impact velocities, the incident waves of the $\mathrm{W} \longrightarrow \mathrm{B}$ and $\mathrm{B} \longrightarrow \mathrm{W}$ samples were the same, while the amplitudes of the reflected waves and the transmitted waves were quite different. This difference was obvious under low impact velocities $(7 \sim 10 \mathrm{~m} / \mathrm{s})$ but less pronounced under high ones $(10 \sim 13 \mathrm{~m} / \mathrm{s})$. From the analysis of stress wave propagation characteristics, it can be seen that the larger the wave impedance of the rock, the better the

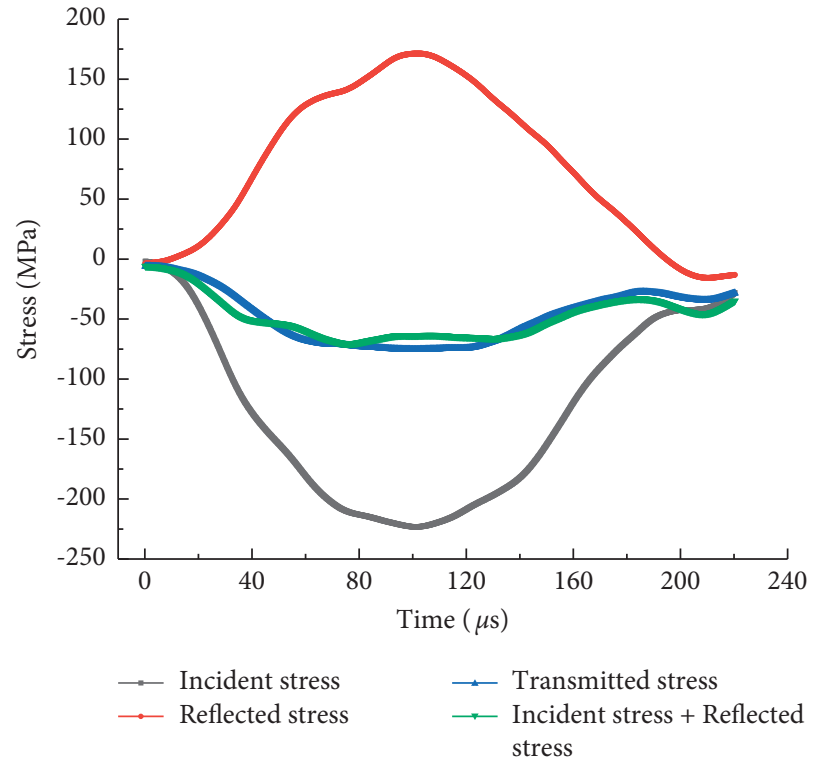

Figure 4: Verification of dynamic stress balance for a typical sample.

impedance matching effect between composite rocks and the incident bar. As a result, when the incident wave propagated to the interface between the composite rocks and the incident bar, more stress waves passed through the composite rocks to the transmitted bar. Therefore, under the same impact velocities, the amplitude of the transmitted wave of the $\mathrm{B} \longrightarrow \mathrm{W}$ sample was larger than that of the $\mathrm{W} \longrightarrow \mathrm{B}$ one. However, with increased impact velocity, the wave impedance matching effect between the sample and the incident bar on the stress wave propagation gradually decreased. Consequently, the shape and amplitude of the stress waves of the two samples became quite close. 

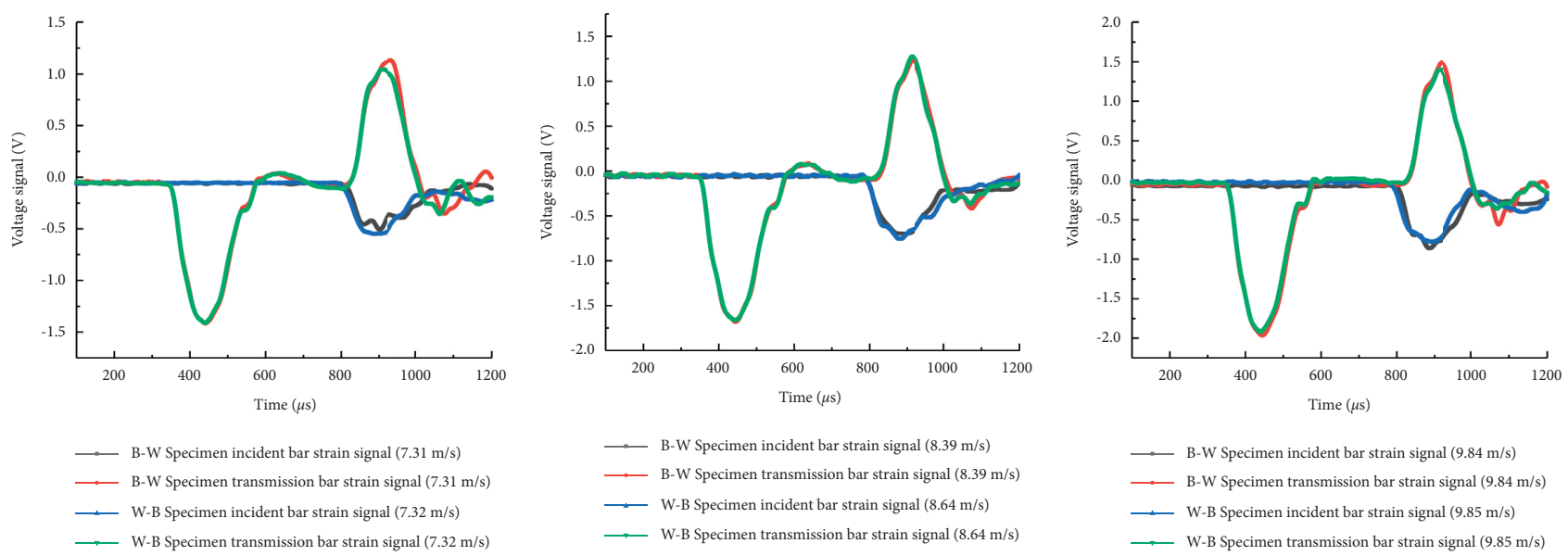

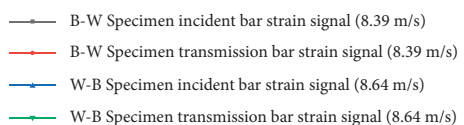

(b)

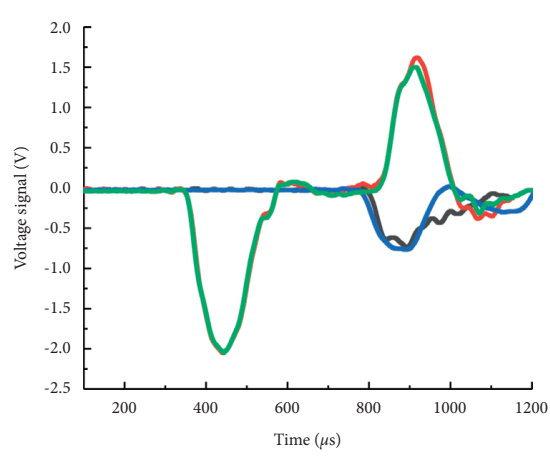

$\square$ B-W Specimen incident bar strain signal $(10.56 \mathrm{~m} / \mathrm{s})$
$\ldots \quad$ B-W Specimen transmission bar strain signal $(10.56 \mathrm{~m} / \mathrm{s})$
$\square \quad$ W-B Specimen incident bar strain signal $(10.58 \mathrm{~m} / \mathrm{s})$
$\square \quad$ W-B Specimen transmission bar strain signal $(10.58 \mathrm{~m} / \mathrm{s})$

(d)
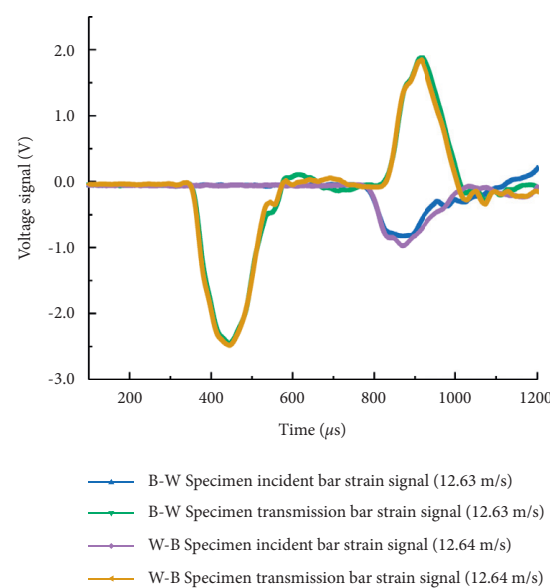

(e)

Figure 5: Waveforms of $\mathrm{B} \longrightarrow \mathrm{W}$ and $\mathrm{W} \longrightarrow \mathrm{B}$ composite rock samples at different impact velocities. (a) $7.2 \mathrm{~m} / \mathrm{s}$. (b) $8.6 \mathrm{~m} / \mathrm{s}$. (c) $9.8 \mathrm{~m} / \mathrm{s}$. (d) $10.4 \mathrm{~m} / \mathrm{s}$. (e) $12.6 \mathrm{~m} / \mathrm{s}$.

3.2. Analysis of Energy Dissipation. According to the thermodynamics theory, the material fracture is an energydriven state instability phenomenon. The deformation and failure of layered composite rocks occur through the accumulation, migration, and dissipation of energy [30]. Therefore, the study of the energy dissipation under impact loading and the analysis of the damage characteristics of layered composite rocks from the energy standpoint is of great significance to better understand the energy absorption characteristics of layered composite rocks and to improve the anti-impact characteristics of the layered composite surrounding rock bearing structure of the roadway in a targeted manner. According to the one-dimensional elastic wave theory, the incident, reflected, and transmitted energies during the impact test can be calculated via the following equations [25]:

$$
\begin{aligned}
& W_{I}=\operatorname{AEC}_{B} \int \varepsilon_{I}^{2}(t) d t, \\
& W_{R}=\operatorname{AEC}_{B} \int \varepsilon_{R}^{2}(t) \mathrm{d} t,
\end{aligned}
$$

$$
W_{T}=\mathrm{AEC}_{B} \int \varepsilon_{T}^{2}(t) \mathrm{d} t,
$$

where $\mathrm{W}_{I}, \mathrm{~W}_{R}$, and $\mathrm{W}_{T}$ represent incident, reflected, and transmitted energies, respectively; $\varepsilon_{\mathrm{I}}(t), \varepsilon_{R}(t)$, and $\varepsilon_{T}(t)$ are the incident, reflected, and transmitted strains at time $t$, respectively; and $A, E$, and $C_{B}$ are the cross-sectional area, the elastic modulus, and the propagation velocity of longitudinal waves of the pressure bar, respectively.

Formulas (1)-(3) were used to calculate the energy evolution curves of typical layered composite rocks under impact loading, as shown in Figure 6. It can be seen that the incident, reflected, transmitted, and absorption energies increased with time. To facilitate analysis, the energy evolution curves of layered composite rocks can be subdivided into the following three stages: slow growth stage, accelerated growth stage, and stable stage. In the slow growth stage $(0 \sim 50 \mu \mathrm{s})$, the composite rocks were in the initial period of stress wave action, and each energy increment was low. Composite rocks mainly experienced elastic deformation with a few microcracks developed inside. Most of the absorbed energy was stored in composite rocks in the form 


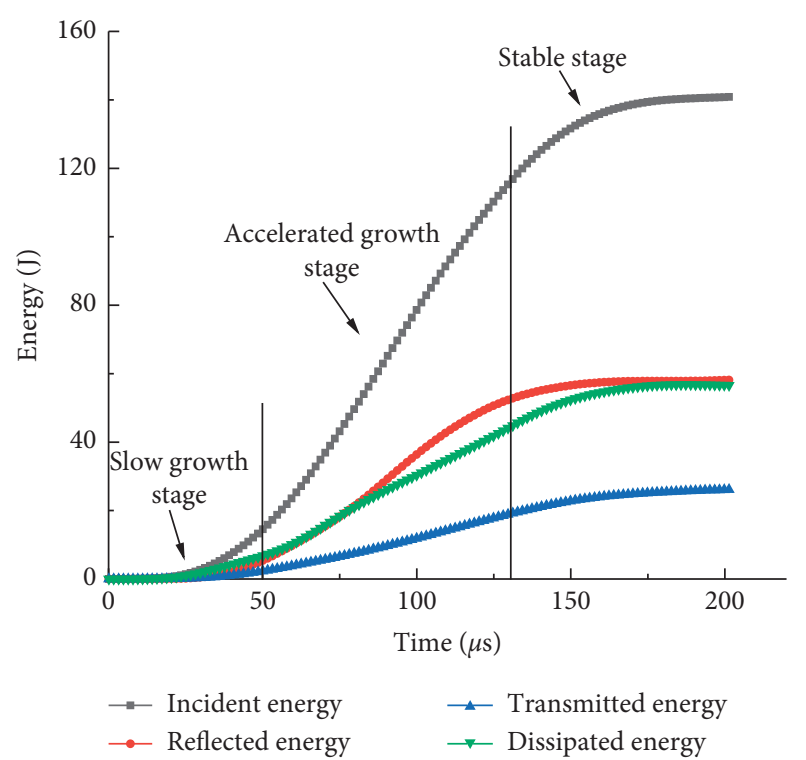

FIGURE 6: Energy evolution curve of typical layered composite rock mass.

of elastic energy. After entering the accelerated growth stage $(50 \sim 150 \mu \mathrm{s})$, the sample energies grew approximately linearly with time. The growth rate of the incident energy was the largest, while that of the transmitted energy was the smallest. The performed analysis revealed that after the stress wave reached the incident bar-sample interface, it would be partly reflected and partly transmitted due to the difference in wave impedance between the two. The transmitted stress wave propagated back and forth in the incident bar, sample, and transmitted bar, continuously supplementing the reflected and transmitted energies. When the stress intensity exceeded the ultimate strength of the rock, the damage and failure in the composite rocks would change qualitatively. Numerous microcracks initiated in the composite rocks rapidly expanded and coalesced, forming macrocracks and continuously increasing the absorption energy. In the stable stage $(150 \sim 200 \mu \mathrm{s})$, the composite rocks failed under the impact load, and the accumulated elastic energy was abruptly released. The energy transfer stopped, and eventually, the energy fluctuations stabilized.

According to the principle of energy conservation, with disregard of the energy loss caused by friction between the pressure bar and the sample during the stress wave propagation, the energy $\mathrm{W}_{A}$ absorbed by the layered composite rock sample under the action of impact load is [31]

$$
W_{A}=W_{I}-W_{R}-W_{T} .
$$

According to the energy dissipation characteristics, the energy $\mathrm{W}_{A}$ absorbed by the sample can be subdivided into the crack growth energy $\mathrm{W}_{F}$, broken block projectile kinetic energy $\mathrm{W}_{D}$, and other forms of energy consumption $\mathrm{W}_{O}$. The latter mainly refers to the energy dissipated in other forms, such as heat energy, which usually can be ignored. The relationship between these energies is as follows:

$$
W_{A}=W_{F}-W_{D}-W_{O} .
$$

Previous studies have shown that, compared with the crack growth energy $\mathrm{W}_{F}$, the projectile kinetic energy of the broken block $\mathrm{W}_{D}$ accounts for a small share. Therefore, the energy absorbed by the sample $\mathrm{W}_{A}$ is approximately equal to the energy consumption in crack propagation $\mathrm{W}_{F}$ [32]; that is, $\mathrm{W}_{A} \approx \mathrm{W}_{F}$.

Rock fragmentation is closely related to energy dissipation and rock volume. Compared with the energy dissipation per unit volume of rock, it can better reflect the energy absorption of rock fragmentation. Therefore, the fragmentation energy density is used to characterize the energy dissipation of rock fragmentation.

$$
\varepsilon_{d}=\frac{W_{A}}{V}=\frac{W_{F}}{V},
$$

where $\varepsilon_{d}$ is the fragmentation energy density and $V$ is the sample volume.

Using equations (1)-(6), the distributions of respective energies in different samples were calculated and are plotted in Table 2. In the energy accumulation and dissipation processes occurring in composite rocks, the reflected energy $W_{R}$ characterizes the propagation ability of the stress wave at the bar-sample interface. The fragmentation energy density $\varepsilon_{d}$ reflects the sample's ability to absorb energy for crack propagation. Therefore, the following analysis mainly focuses on the variations of the reflected energy of the sample and $\varepsilon_{d}$ with incident energy $\mathrm{W}_{I}$.

According to the data in Table 2, the average values of each group were derived and are plotted in Figure 7 . Figure 7(a) shows that the incident energy increased linearly with impact velocity, regardless of the sample type. Figure 5(b) shows that the reflected energy increased approximately as a quadratic function of the incident energy. When the latter was small, the reflected energy of $\mathrm{B} \longrightarrow \mathrm{W}$ composite rocks significantly exceeded that of $\mathrm{W} \longrightarrow \mathrm{B}$ ones. However, with increased incident energy, the difference in reflected energies of the two groups gradually decreased. At the incident energy of 230J, the reflected energies of the two were the same. Based on the analysis of the stress wave propagation characteristics in Section 3.1, when the stress waves reached the interface between the sample and the incident bar, more energy was transferred through the $\mathrm{W} \longrightarrow \mathrm{B}$ composite rock samples because they had a better impedance matching effect with the incident bar than $\mathrm{B} \longrightarrow \mathrm{W}$ samples. Therefore, the reflected energy of $\mathrm{W} \longrightarrow \mathrm{B}$ composite rocks was relatively small. However, with increased impact velocity, the difference in impedance matching effects gradually weakened, and the reflected energy values in the two groups got closer to each other. It can be seen in Figure 7(c) that, given the difference in the impedance matching effects, the fragmentation energy density had the same trend with the incident energy: it behaves as a quadratic function of incident energy. When the incident energy was small, the fragmentation energy density of $\mathrm{W} \longrightarrow \mathrm{B}$ composite rocks was significantly larger than that of $\mathrm{B} \longrightarrow \mathrm{W}$ ones, but the two gradually became close as the incident energy increased. Due to a better impedance matching effect of $\mathrm{W} \longrightarrow \mathrm{B}$ composite rocks, they 
TABLE 2: Energy distribution of layered composite rock mass.

\begin{tabular}{|c|c|c|c|c|c|}
\hline $\begin{array}{l}\text { Sample } \\
\text { type }\end{array}$ & $\begin{array}{c}\text { Impact velocity } \\
(\mathrm{m} / \mathrm{s})\end{array}$ & $\begin{array}{l}\text { Incident energy } W_{I} \\
(\mathrm{~J})\end{array}$ & $\begin{array}{c}\text { Reflected energy } W_{R} \\
(\mathrm{~J})\end{array}$ & $\begin{array}{c}\text { Absorbed energy } W_{A} \\
(\mathrm{~J})\end{array}$ & $\begin{array}{c}\text { Fragmentation energy density } \varepsilon_{d} \\
\left(\mathrm{~J} \cdot \mathrm{cm}^{-3}\right)\end{array}$ \\
\hline \multirow{3}{*}{$\mathrm{B} \longrightarrow \mathrm{W}$} & 7.31 & 79.671 & 43.542 & 24.643 & 0.251 \\
\hline & 7.35 & 78.732 & 41.806 & 24.957 & 0.254 \\
\hline & 7.29 & 77.814 & 43.809 & 25.212 & 0.257 \\
\hline \multirow{3}{*}{$\mathrm{W} \longrightarrow \mathrm{B}$} & 7.27 & 79.451 & 38.113 & 27.284 & 0.278 \\
\hline & 7.32 & 79.135 & 37.508 & 28.566 & 0.291 \\
\hline & 7.25 & 76.674 & 32.738 & 26.374 & 0.269 \\
\hline \multirow{3}{*}{$\mathrm{B} \longrightarrow \mathrm{W}$} & 8.39 & 109.912 & 52.597 & 32.217 & 0.328 \\
\hline & 8.38 & 111.217 & 51.165 & 35.033 & 0.357 \\
\hline & 8.28 & 109.384 & 55.786 & 32.487 & 0.331 \\
\hline \multirow{3}{*}{$\mathrm{W} \longrightarrow \mathrm{B}$} & 8.64 & 109.174 & 48.525 & 37.216 & 0.379 \\
\hline & 8.54 & 108.317 & 50.743 & 39.211 & 0.446 \\
\hline & 8.58 & 103.751 & 44.538 & 34.653 & 0.353 \\
\hline \multirow{3}{*}{$\mathrm{B} \longrightarrow \mathrm{W}$} & 9.95 & 149.788 & 66.433 & 53.068 & 0.541 \\
\hline & 9.84 & 145.979 & 65.691 & 50.947 & 0.519 \\
\hline & 9.76 & 143.522 & 61.714 & 51.955 & 0.529 \\
\hline \multirow{3}{*}{$\mathrm{W} \longrightarrow \mathrm{B}$} & 9.66 & 140.853 & 58.13 & 56.614 & 0.577 \\
\hline & 9.85 & 145.947 & 61.46 & 59.984 & 0.611 \\
\hline & 9.87 & 146.586 & 60.169 & 58.341 & 0.595 \\
\hline \multirow{3}{*}{$\mathrm{B} \longrightarrow \mathrm{W}$} & 10.47 & 161.287 & 72.245 & 62.865 & 0.641 \\
\hline & 10.56 & 164.523 & 70.745 & 64.328 & 0.656 \\
\hline & 10.44 & 160.994 & 74.057 & 65.686 & 0.669 \\
\hline \multirow{3}{*}{$\mathrm{W} \longrightarrow \mathrm{B}$} & 10.57 & 159.715 & 70.686 & 66.086 & 0.673 \\
\hline & 10.64 & 166.827 & 70.067 & 67.899 & 0.692 \\
\hline & 10.58 & 165.183 & 71.029 & 69.542 & 0.709 \\
\hline \multirow{3}{*}{$\mathrm{B} \longrightarrow \mathrm{W}$} & 12.63 & 232.084 & 109.443 & 93.681 & 0.955 \\
\hline & 12.62 & 229.321 & 105.488 & 90.352 & 0.921 \\
\hline & 12.57 & 228.594 & 107.439 & 88.466 & 0.902 \\
\hline \multirow{3}{*}{$\mathrm{W} \longrightarrow \mathrm{B}$} & 12.78 & 238.477 & 110.756 & 91.942 & 0.937 \\
\hline & 12.64 & 232.635 & 104.686 & 91.193 & 0.929 \\
\hline & 12.41 & 222.971 & 102.567 & 91.641 & 0.934 \\
\hline
\end{tabular}

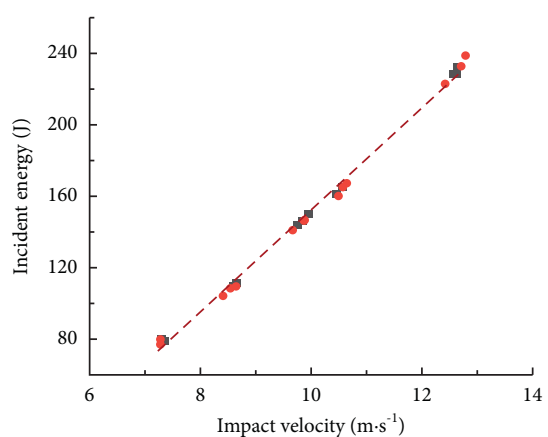

- $\mathrm{B} \rightarrow \mathrm{W}$ composite rocks

- $\mathrm{W} \rightarrow \mathrm{B}$ composite rocks

(a)

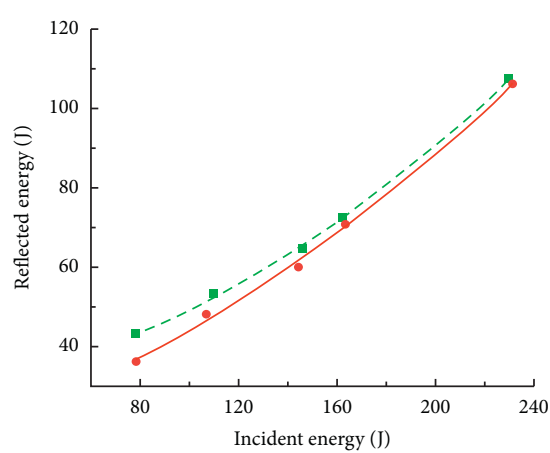

- $\quad \mathrm{B} \rightarrow \mathrm{W}$ composite rocks

- $\quad \mathrm{W} \rightarrow \mathrm{B}$ composite rocks

Fitting curve of $\mathrm{B} \rightarrow \mathrm{W}$ composite rocks $\left(\mathrm{R}^{2}=0.998\right)$

Fitting curve of $\mathrm{B} \rightarrow \mathrm{W}$ composite rocks $\left(\mathrm{R}^{2}=0.996\right)$

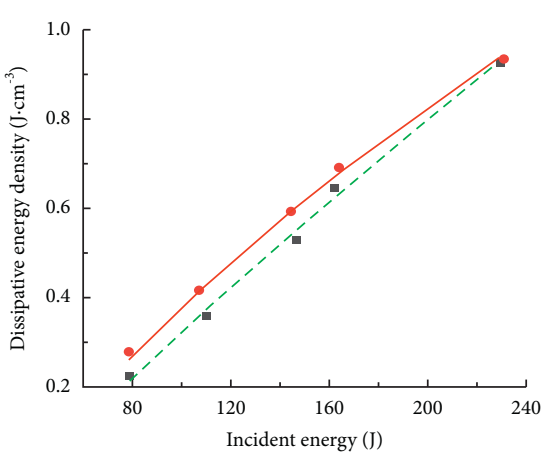

- $\quad \mathrm{B} \rightarrow \mathrm{W}$ composite rocks

- $\quad \mathrm{W} \rightarrow \mathrm{B}$ composite rocks

- - - Fitting curve of $\mathrm{W} \rightarrow \mathrm{B}$ composite rocks $\left(R^{2}=0.983\right)$

_ Fitting curve of $\mathrm{B} \rightarrow \mathrm{W}$ composite rocks $\left(\mathrm{R}^{2}=0.988\right)$

(b)

(c)

FIGURE 7: Energy evolution patterns of layered composite rock mass. (a) Impact velocity-incident energy. (b) Incident energy-reflected energy. (c) Incident energy and fragmentation energy density. 
transmitted more energy than $\mathrm{B} \longrightarrow \mathrm{W}$ ones at the same impact velocities. The crack propagation energy consumption $\mathrm{W}_{\mathrm{F}}$ of $\mathrm{W} \longrightarrow \mathrm{B}$ composite rocks was larger, so they were more prone to fragmentation. Therefore, the fragmentation energy density of $\mathrm{W} \longrightarrow \mathrm{B}$ composite rocks was larger at low impact velocities. However, with increased incident energy, the energy input of $\mathrm{W} \longrightarrow \mathrm{B}$ and $\mathrm{W} \longrightarrow \mathrm{B}$ composite rocks tended to be the same, reducing the difference in their fragmentation energy densities.

3.3. Analysis of Failure Characteristics. To study the failure characteristics of layered composite rocks, it is necessary to analyze the stress characteristics and strength conditions at their interface. The development of cracks at the interface of layered composite rocks is closely related to the rocks' mechanical environment and mechanical properties at the interface. To facilitate analysis, it was assumed that when the composite rocks deformed and failed, the adjacent two phases of rock mass underwent no relative displacement, and the binder thickness binder at the interface could be ignored. According to the data in Table 1, the following inequalities hold: $E_{\mathrm{R}}>E_{\mathrm{C}}$ and $\mu_{\mathrm{C}}>\mu_{\mathrm{R}}$, where $E_{\mathrm{R}}$ and $E_{\mathrm{C}}$ are the elastic moduli of black and white sandstones, respectively, while $\mu_{\mathrm{R}}$ and $\mu_{\mathrm{C}}$ are their Poisson's ratios. When layered composite rocks deform and fail due to the difference in Poisson's ratios of their two phases, the radial stress will be restrained at the interface of black and white sandstones. The stresses acting in microunits at this interface are shown in Figure 8.

From the continuity condition of deformation and the static equilibrium equation, it can be obtained that [33]

$$
\sigma_{i R}=\sigma_{i C}=\frac{E_{R} \mu_{C}-E_{C} \mu_{R}}{E_{R}\left(1+\mu_{C}\right)-E_{C}\left(1+\mu_{R}\right)} \sigma_{1},
$$

where $i=2,3$ and $\sigma_{1}=\sigma_{1 \mathrm{R}}=\sigma_{1 \mathrm{C}}$

This study adopted the Drucker-Prager failure criterion, which considers the effects of intermediate principal stress and hydrostatic pressure simultaneously, overcoming the main weakness of the Mohr-Coulomb criterion and making it suitable for rock materials. The criterion can be expressed as

$$
f=\alpha I_{1}+\sqrt{J_{2}}-K=0,
$$

where $I_{1}=\sigma_{1}+\sigma_{2}+\sigma_{3}$ is the first invariant of stress and $J_{2}=\left[\left(\sigma_{1}-\sigma_{2}\right)^{2}+\left(\sigma_{2}-\sigma_{3}\right)^{2}+\left(\sigma_{3}-\sigma_{1}\right)^{2}\right] / 6$ is the second invariant of stress deflection, while $U_{f}=\int_{\varepsilon_{1}}^{\varepsilon_{2}} \sigma_{i}+\sigma_{i+1} / 2 \mathrm{~d} \varepsilon$ and $U_{y}=$ $U_{e}-U_{f}=1 / 2 \sigma_{c} \varepsilon_{e}-\int_{\varepsilon_{1}}^{\varepsilon_{2}} \sigma_{i}+\sigma_{i+1} / 2 \mathrm{~d} \varepsilon$ are experimentally determined constants related to the internal friction angle $\varphi$ and cohesion force $c$ of black and white sandstone rocks.

If $\sigma_{2}=\sigma_{3}$, formula (2) can be simplified as

$$
\sigma_{1}=\frac{3-5 \sin \phi}{3+\sin \phi} \sigma_{3}+\frac{6 c \cos \phi}{3+\sin \phi} \text {. }
$$

If $\sigma_{2}=\sigma_{3}=0$, the strength of the white sandstone far away from the black sandstone-white sandstone (BW) interface can be obtained as

$$
\sigma_{\mathrm{UCS}}=\frac{6 c \cos \phi}{3+\sin \phi} .
$$

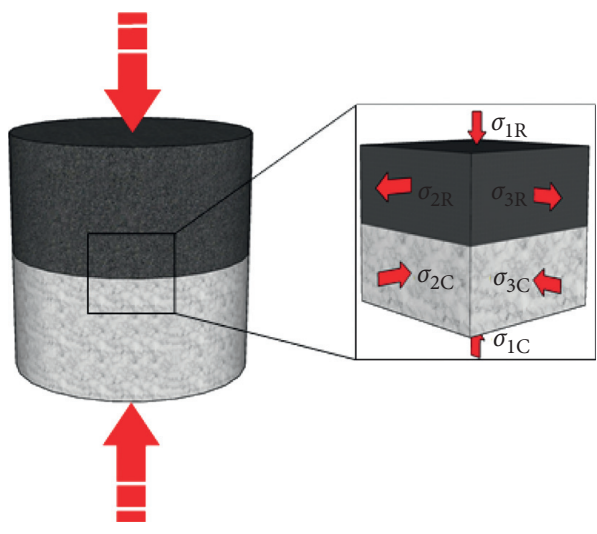

Figure 8: The triaxial stress state in a combined black sandstonewhite sandstone sample and its interface.

According to equations (7)-(11), the strength of white sandstone at the interface can be obtained as

$$
\begin{aligned}
\sigma_{R C} & =\frac{\sigma_{\mathrm{UCS}}}{1-\beta \lambda}, \\
\beta & =\frac{3-5 \sin \varphi}{3+5 \sin \varphi},
\end{aligned}
$$

for $0<\alpha<1$ and $0<\lambda<1$, where $\alpha=(3-5 \sin \varphi)$ $/(3+5 \sin \varphi)$ and

$$
\lambda=1-\frac{E_{R}-E_{C}}{\left(E_{R} \mu_{C}-E_{C} \mu_{R}\right)+\left(E_{R}-E_{C}\right)} .
$$

It can be seen from equation (11) that, in layered composite rocks, the strength of the white sandstone at the interface is strengthened due to the difference in Poisson's ratios, and the strength of the white sandstone far away from the interface is less than the white sandstone strength at the interface. The strength of the black sandstone at the interface is weakened due to the same reason, and the strength of the black sandstone far away from the interface exceeds that of the black sandstone at the interface. Although the stress at both ends of the sample and the elastic modulus and Poisson's ratio of the rock samples change with time under the action of the stress wave, only the stress magnitude changes, but not its direction. That is to say, it only has a certain influence on the degree of weakening or strengthening of the rock mass at the interface. This effect may be less pronounced than the true stress concentration effect, but it does exist theoretically, directly affecting the initiation, expansion, and arrest of the cracks at the interface.

The high-speed camera was used to observe the deformation and failure process of layered composite rocks. Using the initial speckle image of layered composite rocks during impact loading as a reference and setting the time when the incident wave reached the interface between the incident bar and the sample to zero, the speckle images at typical times of impact loading were selected and analyzed using the PhotoInfor and PostViewer digital image processing software packages [34]. Figures 9 and 10 show the failure characteristics and maximum shear strain of $\mathrm{B} \longrightarrow \mathrm{W}$ and $\mathrm{W} \longrightarrow \mathrm{B}$ samples at the impact velocity of $9.8 \mathrm{~m} / \mathrm{s}$, respectively. 


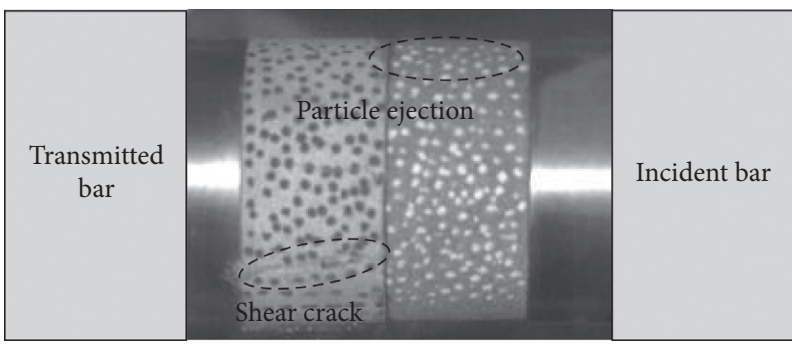

(a)

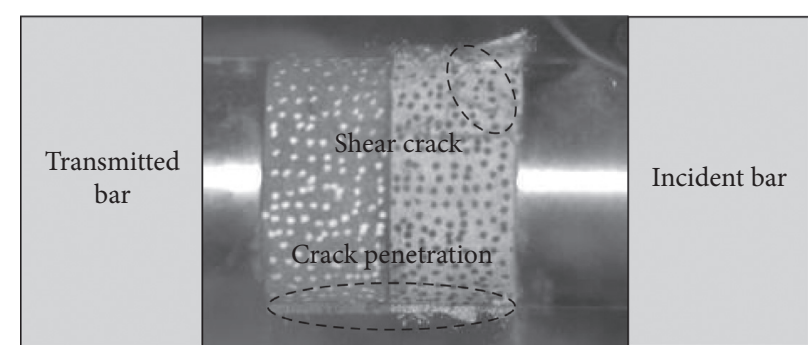

(b)

Figure 9: Failure characteristics of the layered composite rock mass. (a) $\mathrm{B} \longrightarrow \mathrm{W}$ sample. (b) $\mathrm{W} \longrightarrow \mathrm{B}$ sample.

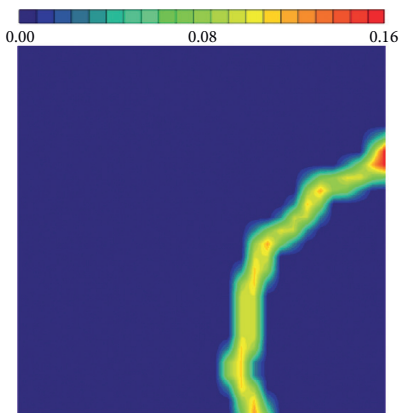

$105 \mu \mathrm{s}$

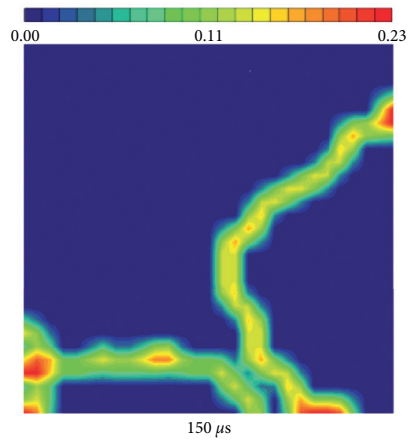

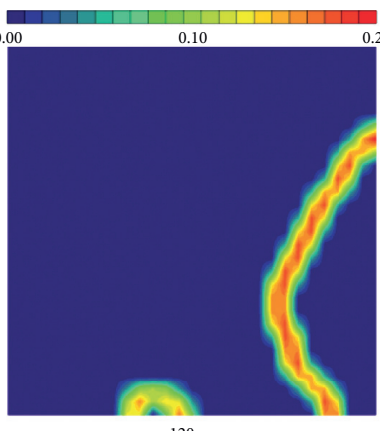

$120 \mu \mathrm{s}$

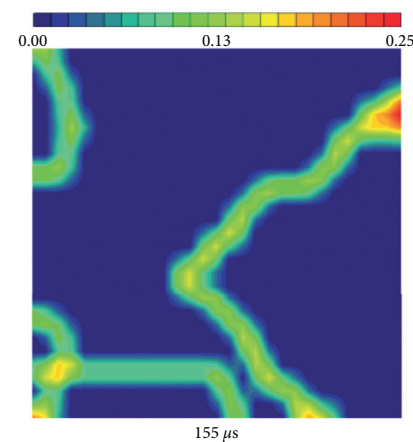

(a)

$135 \mu \mathrm{s}$
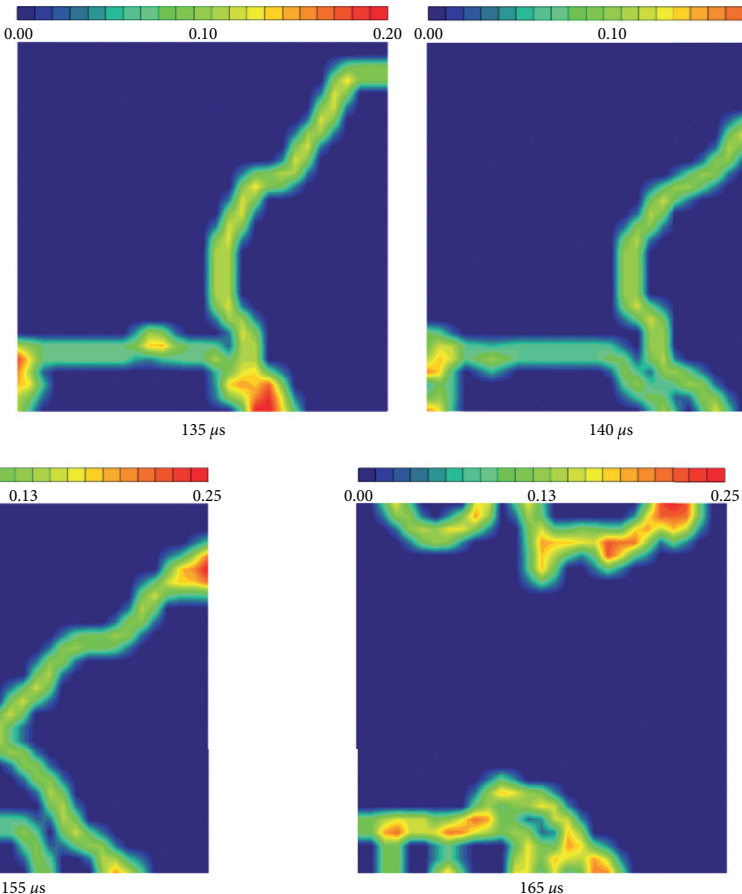

$165 \mu \mathrm{s}$

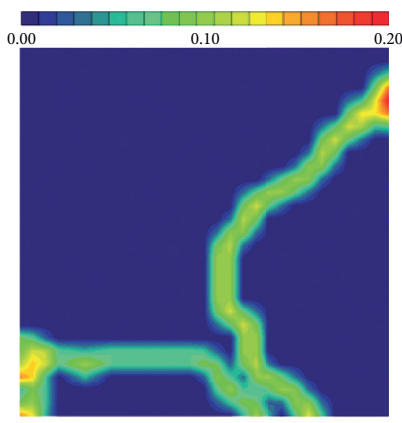

$140 \mu \mathrm{s}$

Figure 10: Continued. 


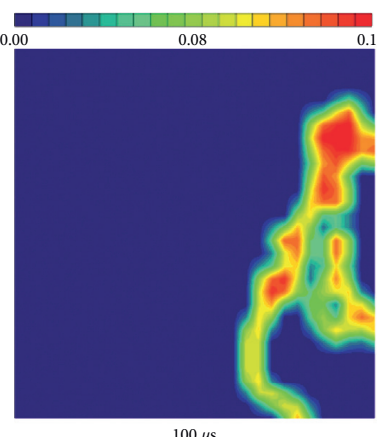

$100 \mu \mathrm{s}$

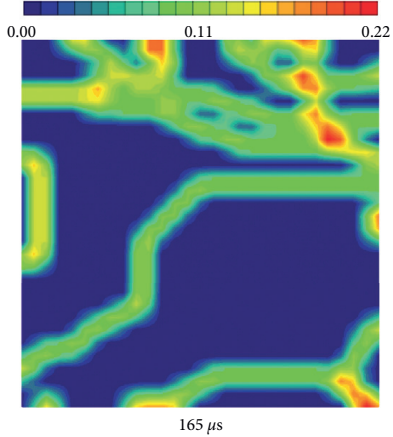

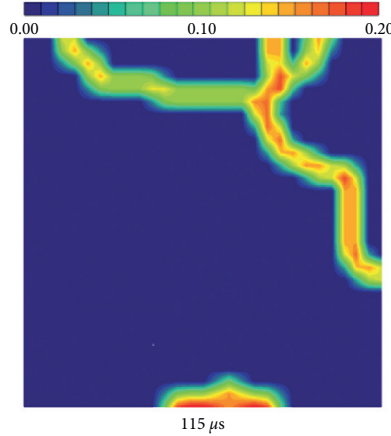
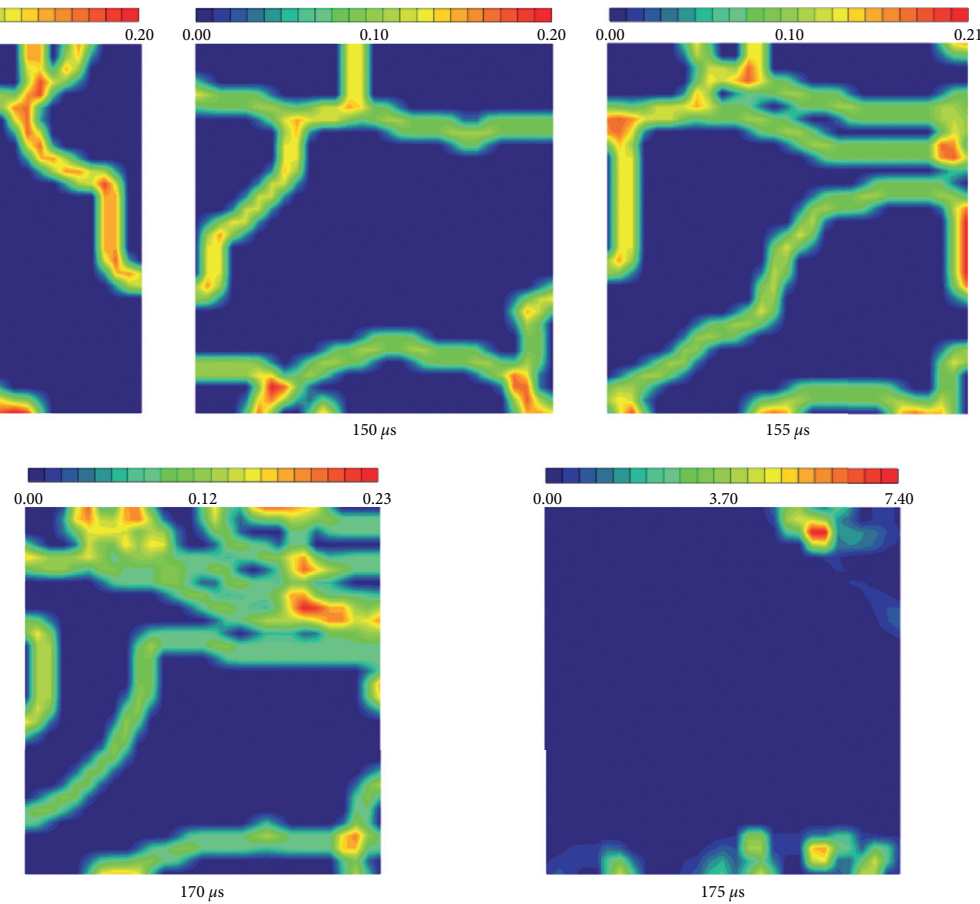

(b)

Figure 10: Maximum shear strain cloud diagram of layered composite rocks $(9.8 \mathrm{~m} / \mathrm{s})$. (a) B $\longrightarrow$ W sample. (b) W $\longrightarrow$ B sample.

It can be seen in Figure 9 that, under the same stress wave, the macrocracks in layered composite rocks started to propagate from the white sandstone surface far away from the interface of the two-phase rock mass, gradually reaching the interface. When such cracks initiated from the white sandstone of the $\mathrm{B} \longrightarrow \mathrm{W}$ sample and reached the interface, the stress at the crack tip was less than the strength of the weakened black sandstone [35]. As a result, the cracks were blocked when they developed into the interface. The black sandstone component experienced only the ejection of particles with no macrocracks and, thus, had good integrity. In contrast, more shear cracks developed in the $\mathrm{W} \longrightarrow \mathrm{B}$ sample. The cracks developed from the white sandstone penetrated the interface of the two-phase rock mass, resulting in a higher degree of damage.

It can be seen from Figure 10 that, under the initial action of the stress wave, the maximum shear strain area in the $\mathrm{B} \longrightarrow \mathrm{W}$ composite rocks exhibited an approximate $\mathrm{V}$-shaped distribution. As the stress wave continued to act, the maximum shear strain concentration gradually increased. However, since the shear stress was less than the strength of the black sandstone, the latter underwent elastic deformation only. After the stress wave continued to act for $165 \mu \mathrm{s}$, the composite rocks were damaged, leading to the restoration of local elastic deformation. The maximum shear strain was mainly concentrated on the lower left and upper right sides of the observation area, corresponding to the propagation of shear cracks in the white sandstone of the $\mathrm{B} \longrightarrow \mathrm{W}$ sample and the local particle ejection of the black sandstone. Compared with the $\mathrm{B} \longrightarrow \mathrm{W}$ sample, the $\mathrm{W} \longrightarrow \mathrm{B}$ sample had multiple areas of maximum shear strain concentration, most of which were located on the right side of the observation area, that is, in the white sandstone component. This implies that the deformation and failure of the $\mathrm{W} \longrightarrow \mathrm{B}$ sample were more complicated than those of $\mathrm{W} \longrightarrow \mathrm{B}$ one. After the stress wave acted for $175 \mu$ s, the composite rocks suffered severe compression and shear failure. The maximum shear strain value at the bottom and upper right side of the observation area was 7.4, corresponding to the development and propagation area of shear cracks in the $\mathrm{W} \longrightarrow \mathrm{B}$ sample.

Based on the initiation and development of cracks on the surface of the composite rocks and the maximum shear strain zone evolution, the strength of each area of the composite rocks could be ranked as follows in the increasing order: white sandstone far away from the interface, white sandstone at the interface, black sandstone at the interface, and black sandstone far away from the interface. This ranking is consistent with theoretical analysis results. Other groups of tests showed similar damage characteristics.

\subsection{Analysis of Failure Morphology and Fracture} Characteristics. Broken parts of the tested samples were collected, and the failure morphologies of layered composite rocks under different impact velocities were analyzed and are summarized in Table 3.

It can be seen from Table 3 that, with increased impact velocity, the degree of sample fragmentation gradually intensified. The fragments of the rock sample transitioned from blocky to granular or even powdery forms. The degree of fragmentation of the white sandstone exceeded that of black sandstone, while the rock fragments at the interface 
TABLE 3: Broken morphology of layered composite rock mass.

\begin{tabular}{|c|c|c|}
\hline Impact velocity velocities $\left(\mathrm{m} \cdot \mathrm{s}^{-1}\right)$ & $\mathrm{B} \longrightarrow \mathrm{W}$ sample & $\mathrm{W} \longrightarrow \mathrm{B}$ sample \\
\hline 7.2 & & \\
\hline 8.6 & & \\
\hline 9.8 & & \\
\hline 10.4 & & \\
\hline 12.6 & & \\
\hline
\end{tabular}

still existed in the form of combined bodies. When the impact velocity was small $(7.2 \sim 8.6 \mathrm{~m} / \mathrm{s})$, the integrity of the composite rocks sample was good without the development of macrocracks and only had local granular tensile ejection. At the impact velocity of $9.8 \mathrm{~m} / \mathrm{s}$, the white sandstone reached the energy accumulation limit first. A single-slope shear failure occurred in the white sandstone component of the $\mathrm{B} \longrightarrow \mathrm{W}$ sample, accompanied by local splitting failure. In contrast, the black sandstone component has good integrity without a macroscopic fracture surface. Different from the failure morphology of the $B \longrightarrow W$ sample, the shear cracks in the white sandstone of the $\mathrm{W} \longrightarrow \mathrm{B}$ sample crossed the interface of the two-phase rock mass and developed into the black sandstone, causing the layered composite rocks to undergo a shear failure. The splitting damage of composite rocks increased at high impact velocities $(10 \sim 13 \mathrm{~m} / \mathrm{s})$. Under the staggered penetration of the cracks, the broken combined bodies at the interface were approximately cone-shaped. The larger the impact velocity, the smaller the size of the cone, indicating more severe damage to the sample.

To further analyze the crushing characteristics of layered composite rocks, standard sieves with sieve diameters of $31.5,25,20,16,10,5$, and $2.5 \mathrm{~mm}$ were selected according to the broken blocks' size characteristics, which were then screened and weighed. To intuitively reflect the crushing degree of the sample, the following formula was used to obtain the average particle size $D_{\mathrm{S}}$ of the broken rocks: 


$$
D_{s}=\frac{\sum \beta_{i} D_{i}}{\sum \beta_{i}}
$$

where $D_{i}$ is the average size of broken rock fragments retained on screens of different apertures and $\beta_{i}$ is the mass percentage of broken rocks with a screen aperture of $D_{i}$.

The crushed block's average crushing particle size can be used to compare the fragmentation degree of the layered composite rock samples in a simple and intuitive way, but it cannot directly reflect the distribution characteristics of crushed rock particles. In other words, the same Ds of broken rock mass does not mean that the mass of pieces on each screen is the same. However, the fractal dimension of rock specimens $(D)$ can reflect the degree of rock fragmentation intuitively and quantitatively. Generally, the larger the fractal dimension is, the more and the smaller the volume of the broken block is, indicating that the specimen has a higher crushing degree. The distribution equation of the rock crushing degree can be obtained according to the mass-fragmentation relationship [36, 37]:

$$
\begin{aligned}
& D=3-\alpha, \\
& \alpha=\frac{\lg \left(M_{L_{\mathrm{eq}}} / M\right)}{\lg L_{\mathrm{eq}}},
\end{aligned}
$$

where $M_{\text {Leq }}$ is the mass of broken rocks with the equivalent side length $L_{\text {eq }} ; M$ is the mass of broken rocks within the calculated size; $D$ is the fractal dimension of the fragments; $\alpha$ is the slope value of $M_{\mathrm{Leq}} / M-L_{\mathrm{eq}}$ in double logarithmic coordinates; $M_{\mathrm{Leq}} /$ $M$ is the cumulative percentage of broken rocks with equivalent side length below $L_{\mathrm{eq}}$. The performed calculation of the fractal dimension revealed that the fractal characteristics of composite rock fragments had phase-related patterns, which were not obvious in the entire size range. This phenomenon was also reported by other scholars $[38,39]$. Therefore, to reduce the influence of discrete points on the slope and correlation coefficient of the $\lg \left(M_{\mathrm{Leq}} / M\right)$ and $\lg \left(L_{\mathrm{eq}}\right)$ fitting curves, we selected rock fragments within $2.5 \sim 31.5 \mathrm{~mm}$ to calculate the fractal dimension, as shown in Figure 11.

It can be seen in Figure 11 that, with increased incident energy, the fractal dimension of the composite rocks gradually increased, while the average particle size of the broken rocks gradually decreased. This indicates that the greater the incident energy, the more the broken rocks, the smaller the volume of broken rocks, and the higher the degree of fragmentation. When the incident energy was small, the average particle size of the broken rock of the $\mathrm{W} \longrightarrow \mathrm{B}$ sample was small, and the fractal dimension was large. This implies that the $\mathrm{W} \longrightarrow \mathrm{B}$ samples had a higher crushing degree under the same stress wave than $\mathrm{B} \longrightarrow \mathrm{W}$ ones. But with an increase in incident energy, the two gradually became the same, which is not difficult to understand from an energy perspective. When the incident energy was low, the wave impedance matching effect on the stress wave propagation was stronger, resulting in more energy transmitted to the $\mathrm{W} \longrightarrow \mathrm{B}$ sample with by the same incident wave. In addition, more stress waves were reflected

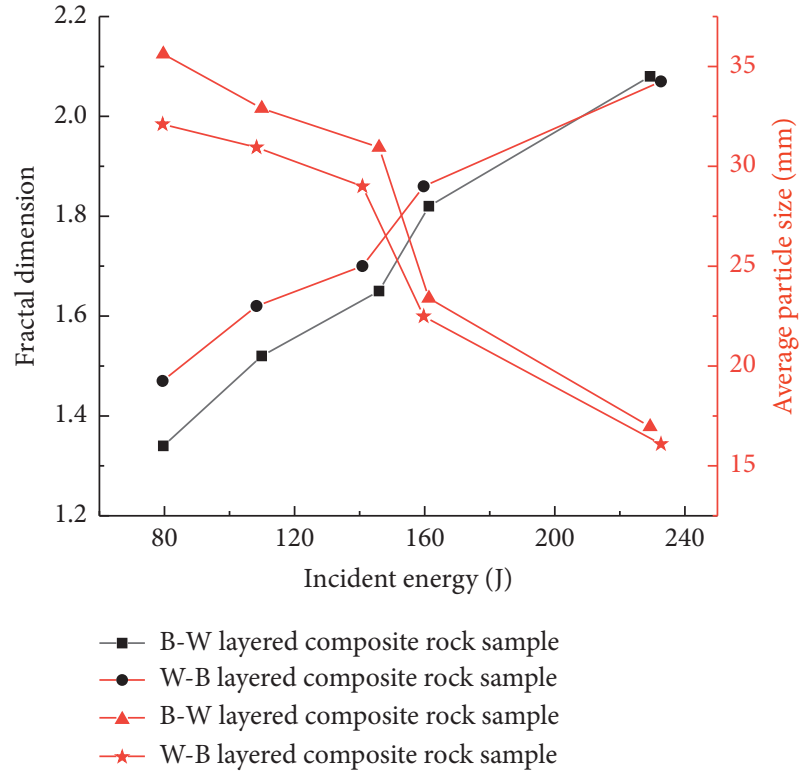

FIGURE 11: Relationship between the fractal dimension and average particle size with incident energy.

by the $\mathrm{W} \longrightarrow \mathrm{B}$ sample when the stress wave propagated from the black sandstone to the transmitted bar. Microcracks in the composite rocks were fully developed under repeated actions of the stress wave, leading to a higher damage degree of the $\mathrm{W} \longrightarrow \mathrm{B}$ sample. On the other hand, due to the low energy accumulation limit of the white sandstone, the white sandstone component of the composite rocks was damaged and failed first under the direct action of the stress wave. For the $\mathrm{W} \longrightarrow \mathrm{B}$ sample, the stress wave directly acted on the white sandstone component through the incident bar, while the stress wave of the $\mathrm{B} \longrightarrow \mathrm{W}$ sample was attenuated through the black sandstone before acting on the white sandstone. Therefore, under the same incident wave, the cracks in the white sandstone component of the $\mathrm{W} \longrightarrow \mathrm{B}$ sample were more developed. At the interface of the two rock components, more cracks developed into the black sandstone rock, resulting in a higher degree of fragmentation of the composite rocks, increasing the fractal dimension and reducing the average particle size of the broken rocks. However, with an increase in incident energy, the black sandstone gradually reached its energy accumulation limit. The wave impedance matching effect was gradually weakened. Therefore, the degrees of fragmentation of the $\mathrm{B} \longrightarrow \mathrm{W}$ and $\mathrm{W} \longrightarrow \mathrm{B}$ samples gradually tended to be the same.

3.5. Study Limitations and Envisaged Follow-Up Steps. After the layered composite rocks were fractured, part of the broken bodies at the interface still existed in a combined form (Table 3), indicating that the fracture process of layered composite rocks was more complicated than that of a single body. When analyzing the deformation and failure of composite rocks, one should not analyze single rock masses separately but take account of their coupling and interface effects. In the follow-up study, the crack initiation, 
propagation, and arrest at the interface will be explored and analyzed from the microstructure standpoint.

When the layered composite rocks deformed and failed, the two rock components affected each other's energy dissipation via the interface effect. The authors plan to determine the broken rock particle size distribution characteristics of single rocks and composite rocks under the same incident energy to further analyze the energy distribution patterns of composite rocks.

\section{Conclusions}

Using the SHPB test system and digital photogrammetry for deformation measurement, the stress wave propagation characteristics, energy evolution pattern, and failure characteristics of layered composite rocks were analyzed and studied. The main conclusions are as follows:

(1) Under the same impact velocity, affected by the wave impedance matching relationship, the stress wave propagation characteristics, energy dissipation pattern, deformation, and fracture characteristics of the $\mathrm{W} \longrightarrow \mathrm{B}$ and $\mathrm{B} \longrightarrow \mathrm{W}$ samples showed obvious differences. Compared with the $\mathrm{B} \longrightarrow \mathrm{W}$ sample, the $\mathrm{W} \longrightarrow \mathrm{B}$ sample had a smaller reflected wave and a larger transmitted wave. Also, the $\mathrm{W} \longrightarrow \mathrm{B}$ sample had smaller reflected energy, a larger dissipated energy density, a larger fractal dimension, and a smaller average particle size of the broken rock. With an increase in impact velocity, the above differences gradually decreased and disappeared.

(2) Under the action of impact load, the energy evolution curve of layered composite rocks had obvious multistage behavior. The reflected energy and fragmentation energy density grew with incident energy approximately as quadratic functions. In the slow growth stage, composite rocks mainly experienced elastic deformation and stored a large amount of elastic energy. After entering the accelerated growth stage, the energy of composite rocks increased approximately linearly with time, and the deformation and failure of samples underwent qualitative changes. After the composite rocks failed, the value of each energy component tended to be stable.

(3) The deformation and failure of composite rocks was a gradual process. According to the initiation and development of surface cracks in the composite rocks and the evolution of the maximum shear strain area, the strength values of the composite rock areas could be ranked as follows in the increasing order: white sandstone far away from the interface, white sandstone at the interface, black sandstone at the interface, and black sandstone far away from the interface.

(4) The damage degrees and failure morphologies of the two-phase composite rocks were quite different. The white sandstone with lower strength and larger wave impedance was fractured more severely. Under high impact velocity, the black sandstone mainly underwent tensile splitting with local shear failure. In contrast, the white sandstone experienced shear failure with local tensile splitting.

\section{Data Availability}

The data used to support the findings of this study are available from the corresponding author upon request.

\section{Conflicts of Interest}

The authors declare that they have no conflicts of interest.

\section{Acknowledgments}

This work was financially supported by the National Key Research and Development Program of China (2016YFC0801402 and 2019YFC1904304) and the Institute of Energy, Hefei Comprehensive National Science Center, under Grant no. 19KZS203.

\section{References}

[1] N. Barton and E. Quadros, "Anisotropy is everywhere, to see, to measure, and to model," Rock Mechanics and Rock Engineering, vol. 48, no. 4, pp. 1323-1339, 2015.

[2] K. Winn, L. N. Y. Wong, and L. R. Alejano, "Multi-approach stability analyses of large caverns excavated in low-angled bedded sedimentary rock masses in Singapore," Engineering Geology, vol. 259, Article ID 105164, 2019.

[3] P.-T. Yeh, K. Z.-Z. Lee, and K.-T. Chang, "3D Effects of permeability and strength anisotropy on the stability of weakly cemented rock slopes subjected to rainfall infiltration," Engineering Geology, vol. 266, Article ID 105459, 2020.

[4] G.-R. Khanlari, M. Heidari, A.-A. Sepahigero, and D. Fereidooni, "Quantification of strength anisotropy of metamorphic rocks of the Hamedan province, Iran, as determined from cylindrical punch, point load and Brazilian tests," Engineering Geology, vol. 169, pp. 80-90, 2014.

[5] H. Kim, J.-W. Cho, I. Song, and K.-B. Min, “Anisotropy of elastic moduli, $\mathrm{P}$-wave velocities, and thermal conductivities of asan gneiss, boryeong shale, and yeoncheon schist in korea," Engineering Geology, vol. 147-148, pp. 68-77, 2012.

[6] J. C. Jaeger, "Shear failure of anistropic rocks," Geological Magazine, vol. 97, no. 1, pp. 65-72, 1960.

[7] Y. M. Tien and M. C. Kuo, "A failure criterion for transversely isotropic rocks," International Journal of Rock Mechanics and Mining Sciences, vol. 38, no. 3, pp. 399-412, 2001.

[8] O. Saeidi, V. Rasouli, R. G. Vaneghi, R. Gholami, and S. R. Torabi, "A modified failure criterion for transversely isotropic rocks," Geoscience Frontiers, vol. 5, no. 2, pp. 215-225, 2014.

[9] S. L. Huang, X. L. Ding, A. Q. Wu, B. Lu, and Y. H. Zhang, "Study of multi-joint constitutive model of layered rock mass and experimental verification," Chinese Journal of Rock Mechanics and Engineering, vol. 31, no. 8, pp. 1627-1635, 2012.

[10] R. H. Cao, R. B. Yao, T. Hu, C. S. Wang, K. H. Li, and J. J. Meng, "Failure and mechanical behavior of transversely isotropic rock under compression-shear tests: laboratory testing and numerical simulation," Engineering Fracture Mechanics, vol. 241, Article ID 107389, 2021.

[11] G. Xu, X. Hu, R. Tang, and Z. Hou, "Fracture evolution of transversely isotropic rocks with a pre-existing flaw under 
compression tests based on moment tensor analysis," Acta Geotechnica, 2021.

[12] V. Maazallahi and A. Majdi, "Numerical appraisal of rock mass anisotropy effect on elastic deformations of a circular tunnel," Arabian Journal of Geosciences, vol. 13, no. 13, p. 547, 2020.

[13] Y. M. Tien, M. C. Kuo, and C. H. Juang, "An experimental investigation of the failure mechanism of simulated transversely isotropic rocks," International Journal of Rock Mechanics and Mining Sciences, vol. 43, no. 8, pp. 1163-1181, 2006.

[14] B. W. Wang, Y. P. Li, C. H. Yang, W. Liu, and G. M. Zhang, "Influences of interface inclination on mechanical properties of composite bedded physical model material," Rock and Soil Mechanics, vol. 36, no. Supp.2, pp. 139-147, 2015.

[15] P. Shen, H. Tang, B. Zhang, Y. Ning, and C. He, "Investigation on the fracture and mechanical behaviors of simulated transversely isotropic rock made of two interbedded materials," Engineering Geology, vol. 286, Article ID 106058, 2021.

[16] S.-Q. Yang, P.-F. Yin, B. Li, and D.-S. Yang, "Behavior of transversely isotropic shale observed in triaxial tests and Brazilian disc tests," International Journal of Rock Mechanics and Mining Sciences, vol. 133, Article ID 104435, 2020.

[17] S. Chen, D. Yin, N. Jiang, F. Wang, and Z. Zhao, "Mechanical properties of oil shale-coal composite samples," International Journal of Rock Mechanics and Mining Sciences, vol. 123, Article ID 104120, 2019.

[18] Z. Yan, Y. Liu, F. Dai, and D. Hongbo, "Dynamic strength and cracking behaviors of single-flawed rock subjected to coupled static-dynamic compression," Rock Mechanics and Rock Engineering, vol. 53, no. 9, pp. 4289-4298, 2020.

[19] Z. Yan, Y. Liu, F. Dai, and D. Hongbo, "Experimental investigations of the dynamic mechanical properties and fracturing behaviors of racked rocks under dynamic loading," Bulletin of Engineering Geology and the Environment, vol. 79, pp. 5535-5552, 2020.

[20] Y. Liu, F. Dai, F. Dong, and N. Xu, "Experimental investigation on the fatigue mechanical properties of intermittently jointed rock models under cyclic uniaxial compression with different loading parameters," Rock Mechanics and Rock Engineering, vol. 51, pp. 47-68, 2018.

[21] X. Shang, Y. Wang, and R. Miao, "Acoustic emission source location from P-wave arrival time corrected data and virtual field optimization method," Mechanical Systems and Signal Processing, vol. 163, Article ID 108129, 2022.

[22] Y. Wang, X. Shang, and K. Peng, "Relocating mining microseismic earthquakes in a $3-\mathrm{D}$ velocity model using a windowed cross-correlation technique," IEEE Access, vol. 8, pp. 37866-37878, 2020.

[23] P. Kang, H. Lv, Q. Zou, Z. Wen, and Y. Zhang, "Evolutionary characteristics of mode-I fracture toughness and fracture energy in granite from different burial depths under hightemperature effect," Engineering Fracture Mechanics, vol. 239, Article ID 107306, 2020.

[24] D. Li, Z. Han, Q. Zhu, Y. Zhang, and P. G. Ranjith, "Stress wave propagation and dynamic behavior of red sandstone with single bonded planar joint at various angles," International Journal of Rock Mechanics and Mining Sciences, vol. 117, pp. 162-170, 2019.

[25] Z. Han, D. Li, T. Zhou, Q. Zhu, and P. G. Ranjith, "Experimental study of stress wave propagation and energy characteristics across rock specimens containing cemented mortar joint with various thicknesses," International Journal of Rock
Mechanics and Mining Sciences, vol. 131, Article ID 104352, 2020.

[26] F. Dai, S. Huang, K. Xia, and Z. Tan, "Some fundamental issues in dynamic compression and tension tests of rocks using split Hopkinson pressure bar," Rock Mechanics and Rock Engineering, vol. 43, no. 6, pp. 657-666, 2010.

[27] G. Gao, W. Yao, K. Xia, and Z. Li, "Investigation of the rate dependence of fracture propagation in rocks using digital image correlation (DIC) method," Engineering Fracture Mechanics, vol. 138, pp. 146-155, 2015.

[28] A. Mardoukhi, Y. Mardoukhi, M. Hokka, and V.-T. Kuokkala, "Effects of heat shock on the dynamic tensile behavior of granitic rocks," Rock Mechanics and Rock Engineering, vol. 50, no. 5, pp. 1171-1182, 2017.

[29] H. Li, H. W. Jing, and Q. Y. Zeng, "Development and application of digital photogrammetry software package for geotechnical engineering," Chinese Journal of Rock Mechanics and Engineering, vol. 25, no. 2, pp. 3859-3866, 2006.

[30] Q. Meng, M. Zhang, L. Han, H. Pu, and T. Nie, "Effects of acoustic emission and energy evolution of rock specimens under the uniaxial cyclic loading and unloading compression," Rock Mechanics and Rock Engineering, vol. 49, no. 10, pp. 3873-3886, 2016.

[31] C. J. Xia, H. P. Xie, Y. Ju, and H. W. Zhou, "Experimental study of energy dissipation of porous rock under impact loading," Engineering Mechanics, vol. 23, no. 9, pp. 1-5, 2006.

[32] Z. X. Zhang, S. Q. Kou, L. G. Jiang, and P.-A. Lindqvist, "Effects of loading rate on rock fracture: fracture characteristics and energy partitioning," International Journal of Rock Mechanics and Mining Sciences, vol. 37, no. 5, pp. 745-762, 2000.

[33] X. F. Xian and X. S. Tan, Failure Mechanism of Layered Rock Mass, Chongqing University Press, Chongqing, 1989.

[34] K. Yang, Z. Wei, L. T. Dou, X. L. Chi, W. J. Liu, and J. Q. Zhang, "Research on dynamic tensile energy evolution and fractal characteristics of water-bearing coal samples," Journal of China Coal Society, vol. 46, no. 2, pp. 398-411, 2021.

[35] K. Yang, W. J. Liu, L. T. Dou, X. L. Chi, Z. Wei, and Q. Fu, "Experimental investigation into interface effect and progressive instability of coal-rock combined specimen," Journal of China Coal Society, vol. 45, no. 5, pp. 1691-1700, 2020.

[36] H. P. Xie, J. N. Wang, and P. G. Qan, "Fractal characters of micropore evolution in marbles," Physics Letters A, vol. 218, no. 3-6, pp. 275-280, 1996.

[37] Y. Deng, M. Chen, Y. Jin, and D. Zou, “Theoretical analysis and experimental research on the energy dissipation of rock crushing based on fractal theory," Journal of Natural Gas Science and Engineering, vol. 33, pp. 231-239, 2016.

[38] T. Deng, L. D. Yang, and W. F. Han, "Influence of loading form on distribution of marble fragments," Journal of Tong Ji University (Natural Science), vol. 35, no. 1, pp. 10-14, 2007.

[39] L. Shi, J. Y. Xu, E. L. Bai, and Z. G. Gao, "Research on impact fracture of rock based on fractal theory," Journal of Vibration and Shock, vol. 32, no. 5, pp. 163-166, 2013. 